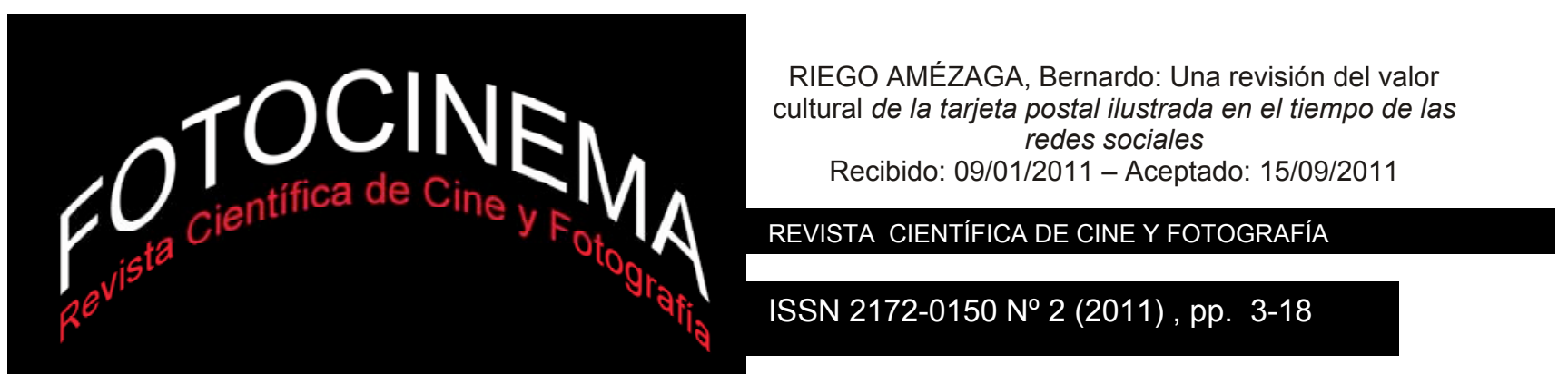

\title{
UNA REVISIÓN DEL VALOR CULTURAL DE LA TARJETA POSTAL ILUSTRADA EN EL TIEMPO DE LAS REDES SOCIALES
}

\section{A REVIEW OF THE CULTURAL VALUE OF THE ILLUSTRATED POSTCARD IN TIME OF SOCIAL NETWORKS}

\section{Bernardo Riego Amézaga \\ Universidad de Cantabria}

\section{Resumen:}

La tarjeta postal ilustrada presenta una serie de interesantes paradojas, es un producto postal nacido en el siglo XIX para la comunicación comercial, pero su verdadero desarrollo tiene lugar en el siglo XX, en el marco de la denominada "sociedad de las masas", gracias a las posibilidades de la reproducción fotomecánica de imágenes que harán posible la sociedad informativa que hoy conocemos.

La tarjeta postal convive en sus usos comunicativos con otros fenómenos culturales como el cine, la prensa gráfica y la emergencia de la fotografía de aficionados. Se revisan en el texto los antecedentes de la tarjeta postal, sus etapas de desarrollo y decadencia y la importancia de la imprenta en la difusión de las imágenes desde el siglo XIX.

\begin{abstract}
:
The illustrated card presents a series of interesting paradoxes, is a postal product born in the nineteenth century for business communications, but its real development takes place in the twentieth century, under the socalled "mass society", thanks the possibilities of the photomechanical reproduction of images that will enable the information society as we know today.

The card uses communication coexists with other cultural phenomena such as film, print media and the emergence of amateur photography. Reviewed in the text history of the postcard, its stages of growth and decay and the importance of printing in the dissemination of images from the nineteenth century.
\end{abstract}

\section{Palabras clave:}

Tarjeta postal, fotografía, fotomecánica, imagen e imprenta

\section{Key words:}

Postcard, photograph, photomechanical, imaging and printing 
Ahora que su uso tradicional ha entrado en decadencia, parece un buen momento para analizar algunos de los valores instituidos por la tarjeta postal ilustrada. Un objeto, considerado durante mucho tiempo como de escaso valor cultural, pero que presenta una serie de interesantes paradojas. Se trata de un producto para las redes postales del siglo XIX que fue diseñado para unas utilidades técnicas y comerciales específicas y que muy pronto fueron extendidas a una amplia gama de usos sociales más allá de su concepción original como objeto postal económico y eficiente. Siendo una invención decimonónica, la tarjeta postal va a desarrollarse, sin embargo, a lo largo del siglo XX, y encontrará en la sociedad de las masas su vehículo ideal, junto a la prensa gráfica, el cinematógrafo y la fotografía de aficionado. De todas estas tendencias se aprovechará también la tarjeta postal ilustrada, hasta el punto de que hoy puede también ser estudiada como un medio que muestra el desarrollo del país en múltiples facetas tanto por el extenso contenido como por la amplitud temática de las imágenes que porta ${ }^{1}$.

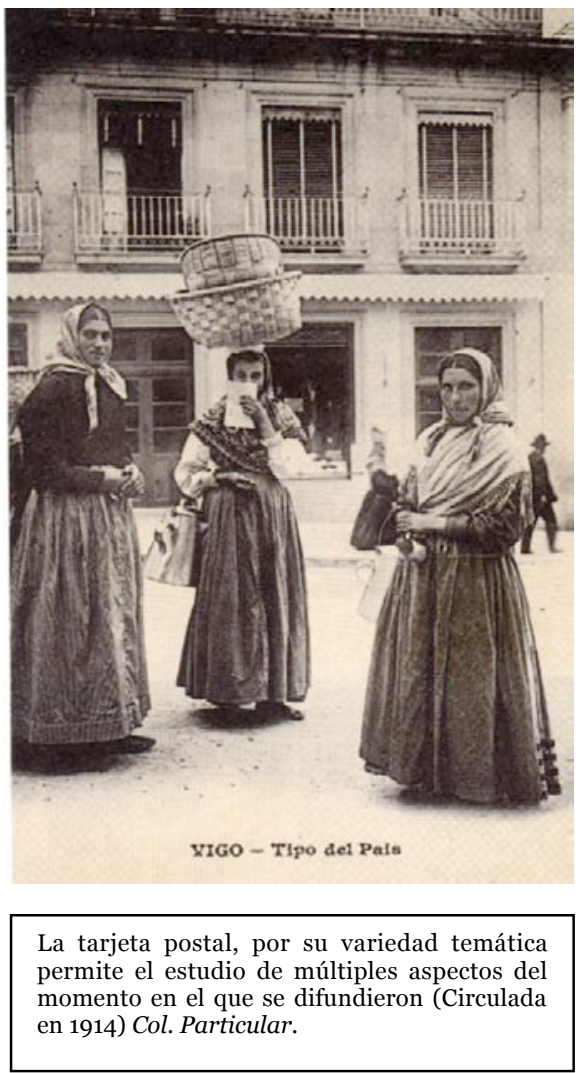
La tarjeta postal ilustrada prefiguró algunas de las cuestiones comunicativas que hoy se están desarrollando en las redes sociales. Nació en el tiempo de la normalización internacional que en el siglo XIX se estaba dando en los

\footnotetext{
1. No ha sido hasta fechas recientes que la tarjeta postal ha sido objeto de interés en la bibliografía española. Hay que destacar desde el coleccionismo los trabajos pioneros de Martín Carrasco Marqués en 1992 interesado en las primeras postales ilustradas producidas en el siglo XIX. La primera aproximación a la catalogación de postales y su apreciación cultural como fenómeno de comunicación llevada a cabo en 1997 por Bernardo Riego Amézaga y Manuela Alonso Laza desde el ejemplo de Santander y el interesante y documentado trabajo histórico de Carlos Teixidor Cadenas publicado en 1999 sobre la tarjeta postal en España de 1892 a 1915. A estos autores se suman otros trabajos que desde perspectivas regionales o locales han valorado estos materiales considerados tradicionalmente efímeros y de poco interés cultural.
} 
servicios y en la industria, como consecuencia de la complejidad que la segunda revolución industrial estaba planteando a los sistemas de producción y distribución, y su invención como un producto postal moderno fue una consecuencia de esa tendencia, por lo que resulta un claro antecedente del fenómeno de la globalización a la que hoy asistimos. Al mismo tiempo, por sus extendidos usos en la sociedad a lo largo del siglo XX, la tarjeta postal puede considerarse como un precedente de las redes sociales, ya que, gracias al coleccionismo postal, personas desconocidas entre si de diferentes países se pusieron en comunicación compartiendo imágenes y temas que les interesaban. La falta de privacidad de los mensajes que transmite (tanto el visual como el escrito) al circular por las redes postales, como un material al descubierto y sin sobre, también prefiguran una característica, la difuminación de lo público y lo privado que hoy es plenamente actual y objeto de debate en las redes digitales, y, por último, fue un fenómeno extensamente compartido en todo el mundo y con un rápido crecimiento exponencial, al igual que podemos apreciar en estos momentos con las redes sociales. Todas estas cuestiones las abordaremos en este breve

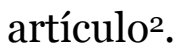

\section{El contexto decimonónico de la tarjeta postal: el papel de la imprenta en la difusión de las imágenes en la sociedad contemporánea}

Comencemos con los aspectos que ligan a la tarjeta postal con la tradición cultural del siglo XIX. Es conocido que su nacimiento como nuevo producto postal tiene lugar en Austria en 1869, donde fue concebida como un medio económico de enviar mensajes breves y todo tipo de comunicaciones de interés industrial o comercial. A mitad de camino entre una carta que respetaba la privacidad de la comunicación y un impreso de circulación más lenta pero económica, la tarjeta postal es un producto moderno, con intención de ser eficiente, y que sacrifica la reserva de la carta cerrada en

\footnotetext{
2. Desde estas perspectivas, hemos revisado el papel cultural de la tarjeta postal ilustrada desde la primera república al franquismo (Sánchez Sánchez et alt, 2011).
} 
beneficio de un formato abierto de tamaño normalizado donde se pueden enviar mensajes rápidos y concretos, encargar pedidos, anotar listados de precios y otros usos que son fruto de un tiempo que está acelerándose de nuevo gracias a la todavía incipiente segunda revolución industrial. En sus primeros momentos de uso nadie piensa en "adornarlas" con imágenes, tan solo se trata de una tipología postal que lleva en el anverso ya franqueado un
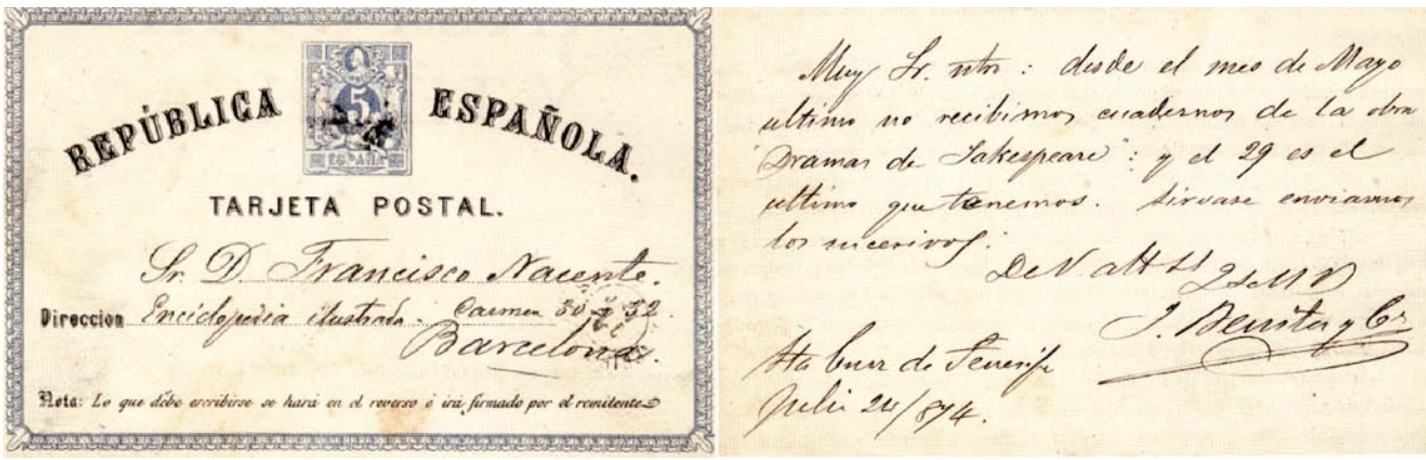

Anverso y reverso de una de las primeras postales editadas para finalidad comercial (1874) Col. Particular.

espacio para poner la dirección y en el reverso un espacio para el mensaje que circulará descubierto por la red postal. En Diciembre de 1873, España adoptará este producto siguiendo la misma tendencia que se está dando en otros muchos países que, además, trabajan para lograr una Unión Postal Universal, es decir, un sistema normalizado de funcionamiento de las redes postales, a través de diversos tratados. España será en 1878 una de las naciones co-fundadoras de este organismo que a comienzos del siglo XX contaba con un número de países que daban cobertura postal a mil ochenta y cuatro millones de habitantes de los mil seiscientos millones que en 1900 comprendían la población mundial. Por lo tanto, la tarjeta postal es un producto internacional que tendrá una enorme y rápida acogida en todas partes. Es en la última década del siglo XIX cuando comienza a experimentarse con añadir imágenes en el espacio del anverso de la tarjeta postal, dejando siempre un espacio en blanco en ese mismo anverso para la dirección. En el caso español las primeras postales con imágenes las realizará Hauser y Menet en 1892 con cuatro vistas de Madrid. Esta experimentación gráfica, como enseguida veremos, tiene relación con unos años en los que se están logrando soluciones satisfactorias para imprimir imágenes fotográficas 
por diversos métodos en la imprenta, y de ese auge tecnológico se aprovechara la tarjeta postal en su expansión social.

Porque la imagen impresa para usos informativos, contaba ya con una larga tradición cuando apareció la tarjeta postal. Aunque es un lugar común suponer que fue la fotografía la que puso en marcha la información gráfica en las sociedades modernas, lo cierto es que la fotografía en su desarrollo tecnológico y como lenguaje comunicativo se encontró con que las revistas

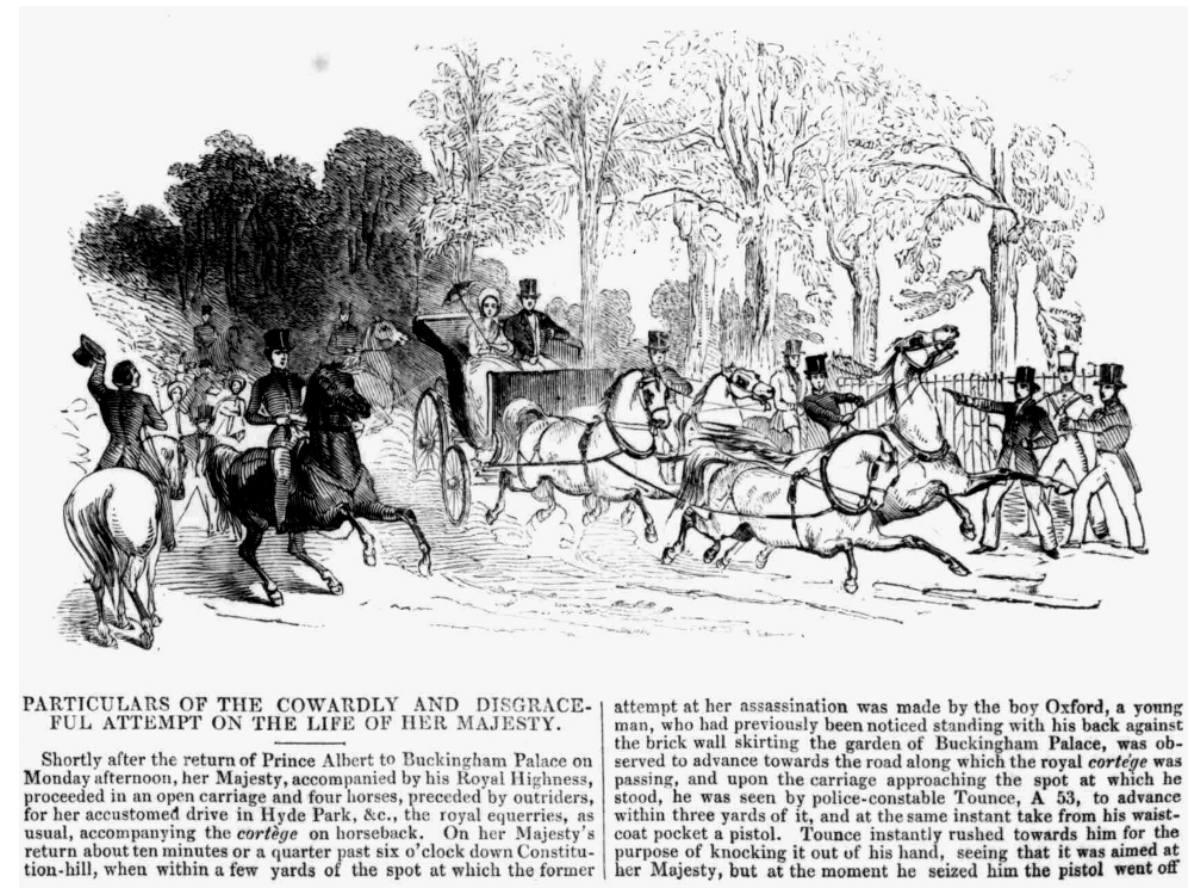

Primeros ensayos de la "actualidad" gráfica. The ilustrated London News julio 1842.

ilustradas habían acometido, incluso antes de su nacimiento oficial como tecnología en 1839, todo un extenso proyecto de difusión informativa basada en imágenes dibujadas (RIEGO, 2001). El primer medio gráfico moderno y predecesor de todos los que actualmente conocemos fueron las revistas ilustradas decimonónicas que catalogaron y mostraron visualmente, primero en grabado en madera y más tarde con otras técnicas de grabado, todo aquello que en su tiempo tenía valor cultural y fueron estas revistas las que introdujeron el concepto de actualidad informativa en las imágenes dibujadas que ofrecían en sus páginas. Se trata de un largo proceso que comenzó en 1822 en el "Penny Magazine” británico, y rápidamente se extenderá el modelo, con más o menos variaciones, por la prensa europea. 
Durante esos años existía un extenso catálogo de grabados de multitud de temáticas a disposición de las revistas que los quisieran adquirir, por lo que es posible encontrarse la misma escena en diversas publicaciones a lo largo del tiempo y tratando temas diferentes. En Julio de 1842, el uso de las imágenes dibujadas en la prensa alcanzó un nuevo estadio cuando "The Illustrated London News” publicó por primera vez una imagen del atentado a la Reina Victoria, mostrando justamente el momento en el que el suceso tuvo lugar. Estamos ante el embrión de la información gráfica de actualidad. En las décadas siguientes asistiremos en la prensa internacional a la conformación de todo un lenguaje gráfico-informativo muy teatralizado y lleno de convenciones, que paulatinamente a su desarrollo irá perdiendo su influencia en la medida que la fotografía va ganando espacio e identidad social y las imágenes obtenidas con una cámara se asimilan a la objetividad indiscutible frente a la "creatividad" de la información dibujada. Hacia 1880, cuatro décadas después de los primeros ensayos de actualidad informativa con dibujos impresos, una nueva generación de lectores que comienzan a consumir la nueva prensa de masas con nuevas temáticas informativas y habituados ya a la presencia de la fotografía y sus usos sociales cada vez más extensos, comienzan a contemplar como anticuadas todo este tipo de informaciones dibujadas que han alcanzado ya una retórica ampulosa y muy predecible en sus intenciones comunicativas.

El cambio tecnológico en las imágenes de imprenta vendrá de la mano de las diversas experiencias de fotograbado que se están ensayando en las últimas décadas del siglo XIX. En el caso español y en una sintonía muy ajustada con las experiencias internacionales, es en la década de 1880 cuando se ensayan algunos métodos para publicar fotografías “directas” esto es, sin la intermediación o la traslación a un dibujo de la imagen captada por la cámara. Es todavía una fase experimental de los diversos métodos de impresión fotomecánica que están ensayándose pero ya evidencia que imágenes con aspecto fotográfico de blancos negros y gama de grises pueden tener cabida en las páginas impresas, algo que hasta la fecha no había sido posible y que transformará la propia concepción del periodismo gráfico en las décadas siguientes. 
En 1885, en el mes de febrero, Heribert Mariezcurrena publicará en las páginas de “La Ilustración” de Barcelona el primer reportaje fotográfico directo en competencia con otras revistas ilustradas que mostrarán esta misma información con los habituales dibujos escenificados. Se trata de imágenes del terremoto de Andalucía acaecido en las navidades anteriores y basta compararlas con las que publican otras revistas aun en dibujo para entender que la naturaleza informativa de la fotografía en las páginas de la prensa tiene unas cualidades bien diferenciadas frente a la tradición de los grabados dibujados.

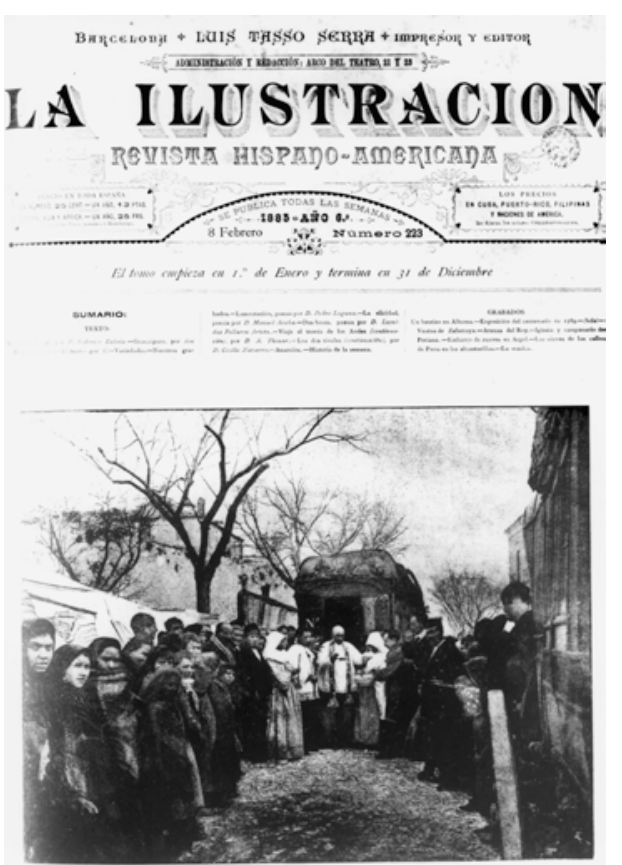

El reportaje fotográfico del terremoto de Andalucía de 1884 fue una experiencia en línea con los experimentos internacionales en técnicas fotomecánicas para la prensa.

Las dos últimas décadas del siglo XIX asistimos a varios fenómenos que recuerdan de algún modo a los momentos actuales donde también con diversas tipologías de información gráfica de naturaleza diferente. Por un lado, la naciente fotografía de prensa aun no tiene una narrativa autónoma y diferenciada como ocurre hoy, por lo que resulta más expresivo el dibujo informativo, y, por el contrario, el valor incontestable de la información fotográfica sigue siendo la veracidad de las imágenes frente a las escenas dibujadas, por ese motivo convivirán hasta el nuevo siglo en las páginas impresas ambas formas gráficas de información, aunque se especializan en sus temáticas en las páginas de las revistas, todavía no ha llegado la instantaneidad a la fotografía, y las informaciones fotográficas de finales del XIX no tienen atractivo visual, pero son fotografías impresas y eso es su gran valor. El proceso de coexistencia de ambas formas gráficas recuerdan un poco a lo que ocurre en la actualidad, y hoy la infografía y la fotografía conviven en el espacio impreso como formas gráficas de información, o la animación en $3 \mathrm{D}$ comparte espacio con las imágenes videográficas para mostrar el alcance de un determinado suceso y el lector o el espectador lo 
acepta como natural. La aparición de una nueva tipología de revistas que dan preeminencia a la imagen fotográfica como vehículo informativo y de las que "Blanco y Negro" fue el más temprano exponente, también permitirán el paulatino desarrollo de un específico lenguaje informativo fotográfico, que irá conformándose en el espacio de las revistas ilustradas que en España, como en todos los países occidentales, van apareciendo a finales del XIX y van a tener una importancia creciente en las primeras décadas del siglo XX, alcanzado su primera madurez en la década de los años treinta, fecha en la que cristalizará todo el desarrollo anterior y harà que en acontecimientos la guerra civil española se consolide el fotoperiodismo contemporáneo3.

\section{Fenómenos culturales del siglo $\mathrm{XX}$ paralelos a la tarjeta postal: el cinematógrafo y los aficionados fotográficos}

Antes de centrarnos en la tarjeta postal, es interesante que revisemos algunos fenómenos culturales que van a surgir en paralelo a su desarrollo y que, también van a tener una cierta influencia en su devenir. Es cierto que durante el siglo XIX "la carte de visite” fue el antecedente más inmediato de la producción y difusión de escenas fotográficas de todo tipo que se destinaban entonces al álbum familiar y alcanzaban en ocasiones grandes tirajes. Prácticamente todos los países tenían una industria fotográfica pequeña o grande que ofrecía este formato de imágenes con todo tipo de temas (CULP DARRAH, 1981). Aunque hoy la "carte de visite" la entendamos mayoritariamente como una moda de retratos, se han conservado muchas imágenes de monumentos, vistas de ciudades, reproducciones de obras de arte y otras tipologías gráficas que responden, como lo hizo la prensa ilustrada y lo hará la tarjeta postal ilustrada posteriormente, a esa tendencia enciclopedista de catalogar y mostrar en imágenes todo lo que se considera de interés cultural en aquellos momentos. La “carte de visite” cederá el paso,

\footnotetext{
3. Figuras como Robert Capa y Gerda Taro, serán reconocidos en este sentido como impulsores decisivos de lo que ahora entendemos como fotoperiodismo contemporáneo, siendo la guerra civil española un verdadero "laboratorio" de la información gráfica moderna. Recientemente, una investigación de Lorna B. Arroyo. Jimenez estudia en profundidad todo este proceso (Arroyo, 2010).
} 
en formato fotográfico, a las escenas estereoscópicas que reconstruyen una sensación de tridimensionalidad en las escenas que se ponen a la venta, una industria que elaborará innumerables vistas de ciudades y países difundiendo arquetipos culturales de cada lugar.

Pero, ciertamente la tarjeta postal ilustrada es un producto del siglo XX y se desarrollará con otros fenómenos culturales con los que tendrá relación. En 1895 se presenta el cinematógrafo como un espectáculo cientifista de barraca de feria ${ }^{4}$ y aunque aparentemente parece que puede tener muy poca relación con la tarjeta postal hay dos puntos de contacto que merece la pena tener en cuenta. Por un lado, los catálogos cinematográficos como los producidos por los Hermanos Lumiere en los primeros años recuerdan en sus temáticas a la propia oferta que se está haciendo de las postales ilustradas. La razón es obvia, el cinematógrafo es un negocio nuevo y en él se tantean los gustos del público sirviéndose de otros productos visuales conocidos en ese momento y que discurren paralelos y tienen buena acogida en el mercado. Por otro lado, el bloc postal, es decir, la frecuente agrupación en diez imágenes postales de una determinada temática, tiene mucha relación con el concepto de secuencia cinematográfica. Se trata de una especie de recorrido visual por un espacio determinado en base a diferentes tomas que componen el conjunto. El bloc postal es una de las formas habituales de ofrecer las postales y su relación secuencial está claramente influenciada por los nuevos hábitos visuales que ha instituido el cinematógrafo.

Otro aspecto relacionado con la tarjeta postal será la aparición en estos mismos años de un nuevo tipo de fotógrafos, que a diferencia de los del siglo XIX, no usan la tecnología fotográfica como medio de subsistencia. Se trata de los “aficionados" , que proceden de las profesionales liberales, o son

4. Sobre la conformación del espectáculo cinematográfico en España existen varios trabajos de gran interés. Es muy revelador, desde la perspectiva provincial, el que publica Juan Carlos de la Madrid (1996): Cinematógrafo y Varietés en Asturias 1896-1915 donde se ve muy bien en esa provincia española la evolución de la barraca de feria a las primeras salas. Un trabajo colectivo que da una idea de conjunto y que fue coordinado también por Juan Carlos de la Madrid (1996): Primeros Tiempos del cinematógrafo en España Ed. Universidad de Oviedo. 5. No disponemos de un trabajo en español dedicado a la fotografía de aficionados de manera global, solo se han publicado algunos trabajos parciales de autores cuyos archivos han ido apareciendo. Una obra que aborda esta época inicial en la que confluye la prensa gráfica, el cine y la fotografía de aficionados es la de Paul Martín (1973): Victorian Snapshots, Arno 
militares o técnicos cualificados, personas adscritas a ese mundo moderno que se esta configurando y que viven por lo general en entornos urbanos y tienen entre sus modernas aficiones fotografiar escenas de la vida cotidiana, en unos años en los que se percibe que, pese a todas las tensiones y resistencias, el país está en un proceso de transformación que irá cambiando las costumbres y los modos de vida. Los aficionados fotográficos y su significado fotográfico es una de las temáticas que requerirían una investigación académica detallada y que sería muy esclarecedora, pues los innumerables archivos fotográficos que están apareciendo en los desvanes, muchas veces sin nombre del autor, nos muestran unas imágenes recurrentes en sus temáticas, en sus gustos por captar lo tradicional en contraste con los aspectos modernos, y que, también difundirán imágenes fotográficas en formato postal, en tirajes en ocasiones únicos, en ocasiones reducidos en cantidad, pero que se incorporan al uso de la postal ilustrada de base fotográfica, ya que los fabricantes de papel sensible, comercializaban este formato llevando ya impreso el anverso con las características

\section{La Guerra en Oriente}

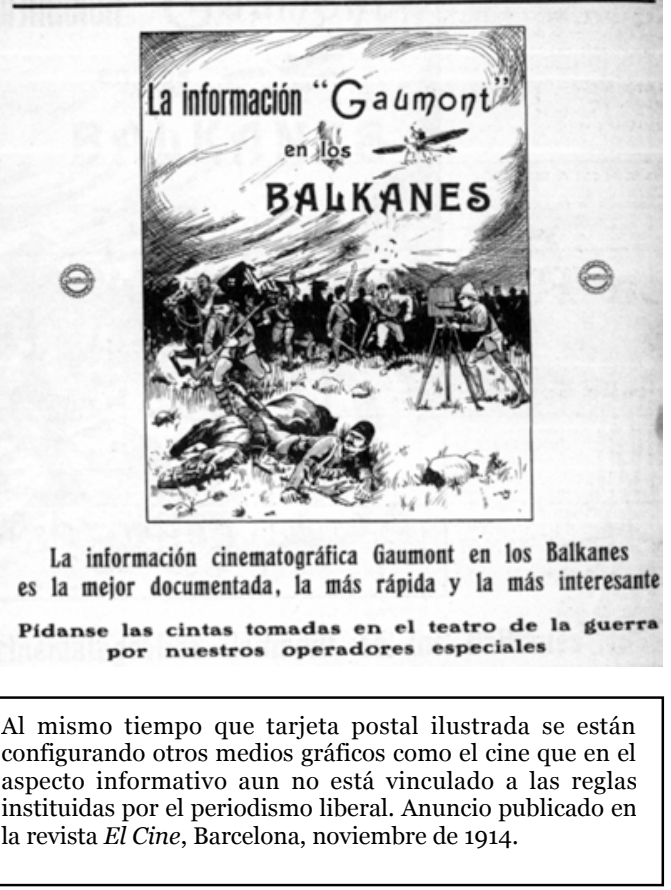

Por lo tanto, el fenómeno postal tiene unas conexiones con otras tendencias que se dan en el momento de su apogeo que coincidirá además con el primer desarrollo de la sociedad de las masas 6 , que está cambiando todos los aspectos de lo cotidiano, desde la relación política que se articula ahora en grandes mítines mientras surge el gusto por los deportes en una sociedad que

Press.

6. Para una comprensión de "la sociedad de las masas" existen muchos trabajo de interés, pero sin duda, para el ámbito español, la obra de Juan Pablo Fusí (1999): Un siglo de España. La Cultura. Ed. Marcial Pons. Madrid, nos proporciona una buena visión de conjunto. 
irá cambiando los modos y escalas de producción industrial, como lo han hecho otras naciones avanzadas antes, mientras que los estados comienzan a preocuparse de la salud y de extender la educación con el fin de insertar a sus ciudadanos en las prácticas y las reglas de la productividad de un tiempo que ya no da valor a lo artesano sino a lo industrial. Una sociedad en suma cada vez más diferente respecto a la decimonónica, que en lo visual consume una nueva prensa gráfica plena de imágenes de fotograbado con temáticas informativas inéditas hasta entonces, se divierte con el cinematógrafo cuyos programas en sus primeros tiempos es una amalgama de ficciones dramáticas o humorísticas junto a películas “naturales" (lo que hoy denominaríamos "documentales de naturaleza”) y que de tanto en tanto introduce "actualidades cinematográficas" que en sus primeros tiempos no tienen una excesiva preocupación por cumplir las reglas de veracidad y objetividad que ya ha instituido de manera sólida el periodismo liberal, por lo que no es raro ver reconstrucciones de acontecimientos muy poco apegados a la veracidad ni a la objetividad informativa. Esa es la sociedad estimulada por nuevas imágenes en diferentes soportes que también colecciona unas tarjetas postales ilustradas que abarcaran todos los temas posibles, incluso algunos que para nuestros gustos actuales nos parecen un poco extraños, pero que responden a esa tendencia al catálogo visual enciclopédico que el nuevo medio postal ha recogido de toda la tradición gráfica precedente.

\section{Auge del postalismo y desarrollo de su lenguaje en el siglo XX}

Aunque las imágenes fotográficas, gracias al soporte fotomecánico, sean la más reproducidas en las cartulinas postales, existen una variedad inmensa de tipologías que aparecerán en el mercado. Las hay dibujadas, adornadas gráficamente con diversos recursos estéticos y en relieve, e incluso perfumadas; pero sin duda el gran campo de experimentación serán las escenas fotográficas de todo tipo que diversos editores sacarán a un mercado que consume millones de postales cada mes, con destino a un coleccionismo que circulará por las redes postales. Prácticamente todos los procesos fotomecánicos se experimentarán en la tarjeta postal y todos los temas 
tendrán cabida en su espacio, por lo que ahora es muy revelador poner en relación unas imágenes con otras y es posible descubrir el desarrollo del país en todos sus aspectos, ya sean productivos, sociales, culturales, urbanísticos, políticos o mostrando acontecimientos de importancia que no solo se recogen en la páginas de la prensa. Así sucesos que golpean a la opinión pública como la Semana Trágica de Barcelona en 1909, o el atentado en la boda de Alfonso XIII en 1906, conocerán varios tirajes en tarjeta postal, junto a la guerra de África y otros temas de actualidad.

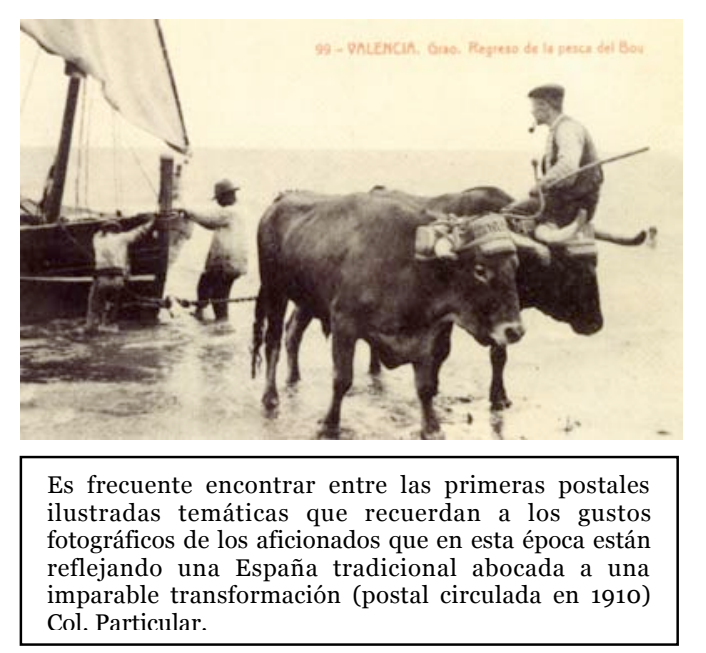

La difusión de las tarjetas postales tiene mucho que ver con una época en la que el coleccionismo es una práctica social en auge y la postal es un producto que simboliza como ningún otro ese tiempo moderno. Los datos de la época expresan ya la circulación ingente de postales. Así Antonio del Campo, un autor que en 1903 escribió un breve opúsculo sobre las postales (DEL CAMPO, 1903), calculaba que el año anterior habían circulado por todo el mundo la cifra de mil millones de postales. Tal vez la cifra sea algo exagerada, pero expresa un movimiento creciente de la tarjeta postal. En España, por ejemplo, la empresa Hauser y Menet cifraba en 1902 su producción mensual en medio millón de postales, y de algunos autores de éxito como Antonio Cánovas del Castillo y Vallejo, más conocido como Kaulak, se decía también en 1902 que había vendido de la serie 'quien supiera escribir' doscientas mil tarjetas, y desde luego los datos que se revelan a partir de las estadísticas anuales de circulación postal estudiadas por Isidro Sánchez Sánchez, Esther Almarcha Nuñez Herrador y Rafael Villena Espinosa, coinciden en que existe una extensa circulación de la tarjeta postal, con cifras inferiores a las de países europeos como Francia, Inglaterra o Alemania (SÁNCHEZ, 2007:22-45).

En 1905 una orden ministerial "libera" el anverso de la tarjeta postal que queda solo para la imagen y el reverso se divide en dos partes para escribir el 
texto y la dirección. En otros países europeos está decisión se había tomado en los años anteriores y supone la apuesta definitiva por la circulación de imágenes para el coleccionismo y las modas sociales sobre la comunicación comercial. Además la tarjeta postal ya se ha convertido en una práctica social y los años siguientes serán los de la maduración del fenómeno y el establecimiento de pautas de uso de las postales que hasta su decadencia hemos conocido. Se establecerán empresas dedicadas a la edición y venta de postales, los fotógrafos encontrarán una vía complementaria de trabajo, y sobre todo el uso de las postales pasará a ser una actividad ampliamente socializada lo que ha permitido que se hayan conservado tantas y tan diversas, debido al alto número que se hicieron y circularon por las redes postales y a la pasión por coleccionarlas.

En la década de los años treinta, durante la guerra civil española, la tarjeta postal será un campo privilegiado de experimentación propagandística de los dos bandos en contienda, apareciendo nuevas modalidades de postales, como las denominadas "postales de campaña” que estaban sometidas a censura y no podían mostrar imágenes de localidades por cuestiones de inteligencia militar. Durante el largo franquismo, la tarjeta postal irá cambiando de formatos y se usará cuando comience la apertura del régimen en la década de los años cincuenta de un modo institucional para difundir una imagen

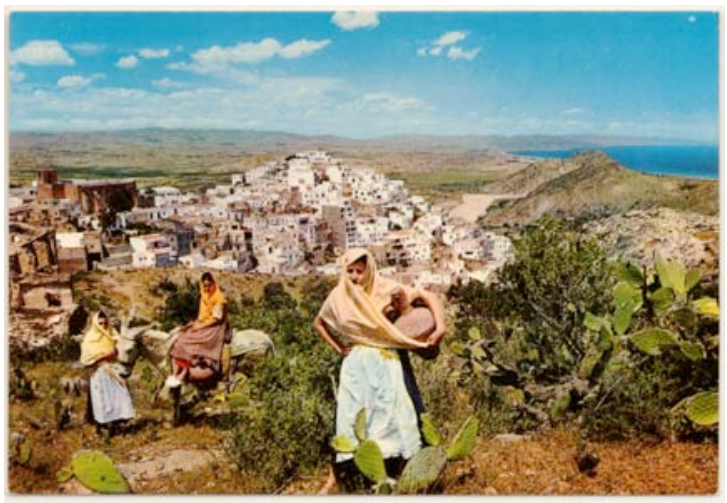

En su etapa de decadencia la tarjeta postal mostrará el desarrollismo español de la época franquista y en algunos de sus temas intentará reproducir una visión nostálgica y falsificada del pasado coincidente con los arquetipos de la imagen turística nacional (imagen de Mojácar editada en 1970) Col. Martín Carrasco Maraués.

"moderna" de una España que a la vez se desea que continúe anclada en los valores tradicionales. Los años del desarrollismo y del primer turismo de sol y de playa nos han dejado una producción de postales coloristas y plastificadas de muy escasa calidad estética pero que son un crudo y realista reflejo de su tiempo, un tiempo ya muy diferente al de las primeras décadas del siglo XX. 
A partir de los años ochenta se atisba ya un cierto declive de la tarjeta postal que muta en otros usos, como expresión artística o producto gratuito con fines publicitarios, y en el nuevo siglo XXI las redes sociales y los usos culturales de las nuevas generaciones han terminado por convertirla en un objeto del pasado, estando en estos momentos en la fase de decadencia, aun cuando siguen editándose y vendiéndose, pero cada vez más los viajeros optan por "colgar" o "subir" sus propias imágenes por Internet o compartirla por las redes sociales en detrimento de enviar un mensaje combinado de texto e imagen a los allegados por las redes postales.

Hoy, las miles y miles de imágenes postales que se han conservado, permiten una extensa mirada en el tiempo, y cada vez son más apreciadas como objeto cultural, además de que los precios de colección aun se mantienen asequibles. Gracias a la tarjeta postal es posible contemplar costumbres desaparecidas, industrias que ya no tienen objeto, fiestas tradicionales y localidades que se han transformado. Se trata en suma de una enciclopedia visual de todo un siglo que ahora, es posible estudiar y valorar como uno de los fenómenos culturales más singulares del siglo XX en un producto que se creó en el siglo XIX.
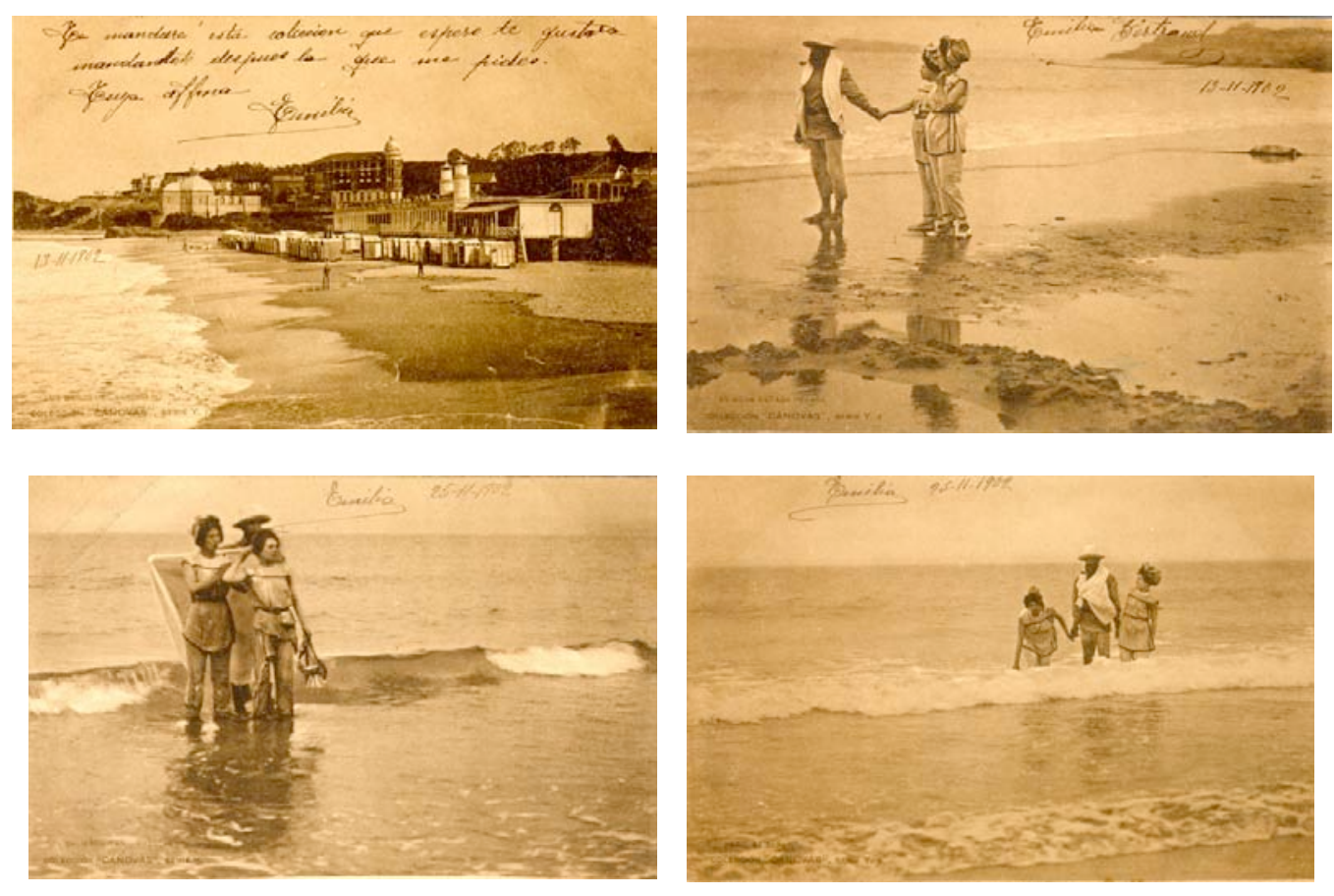

16 

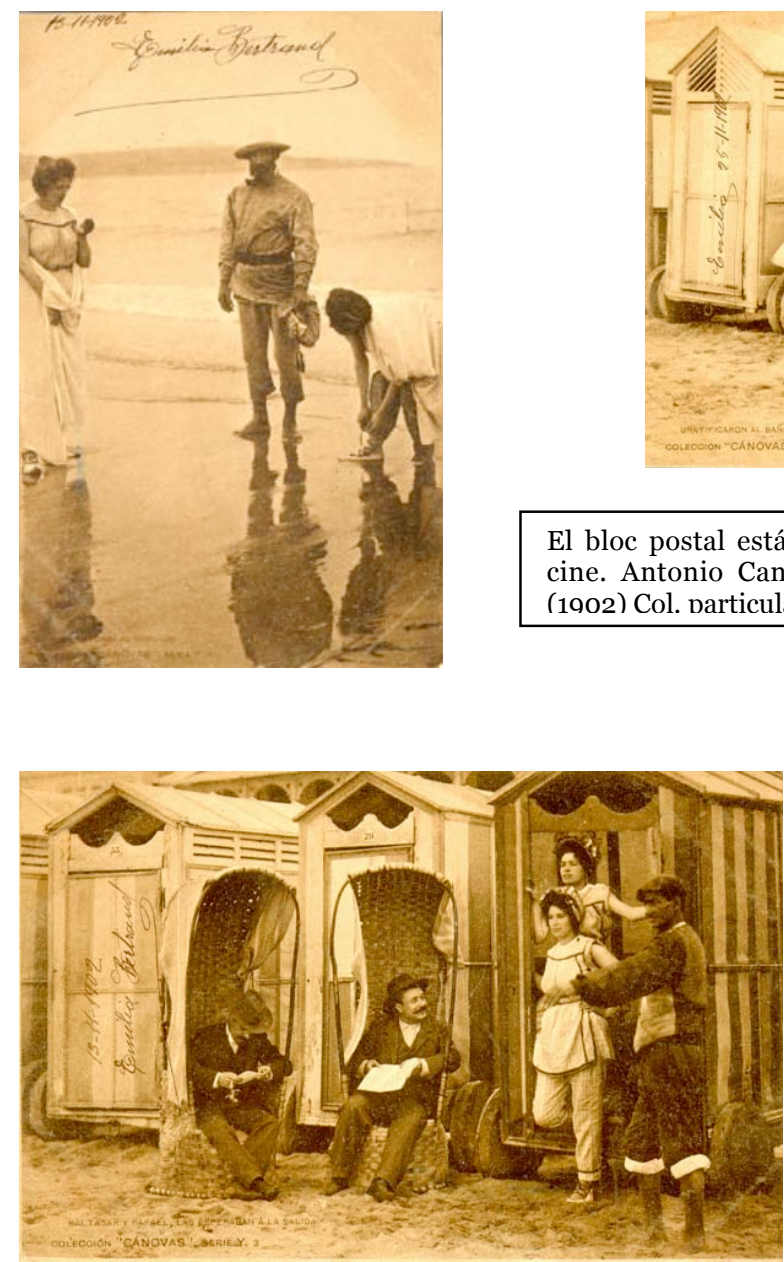

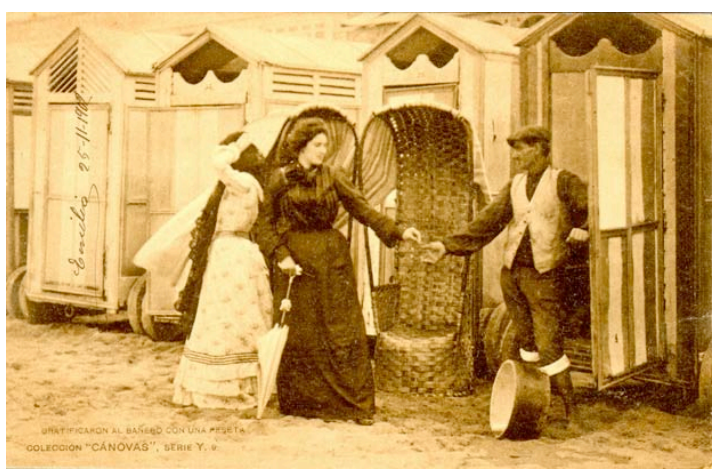

El bloc postal está vinculado a la narración secuencial del cine. Antonio Canovas. Kaulak, Los baños del sardinero (1902) Col. particular.

\section{Referencias Bibliográficas}

ALMARCHA NÚÑEZ-HERRADOR, Esther; FERNÁNDEZ OLALDE, Óscar; SÁNCHEZ SÁNCHEZ, Isidro, RIEGO AMÉZAGA, Bernardo (Editor) y Rafael VILLENA ESPINOSA (2011): España en la tarjeta postal. Un siglo de imágenes. Lunwerg Editores. Barcelona.

ALMARCHA NÚÑEZ-HERRADOR, Esther, FERNÁNDEZ OLALDE, Óscar, SÁNCHEZ SÁNCHEZ, Isidro y VILLENA ESPINOSA, Rafael (2007): "Evocación, historia y tarjetas postales entre repúblicas (1869-1939)", en Fotografía y patrimonio. II Encuentro en Castilla-La Mancha, Centro de Estudios de Castilla la Mancha. Ciudad Real, pp. 22-45.

ARROYO JIMENEZ, Lorna B. (2010): Documentalismo técnico en la guerra civil española. Inicios del Fotoperiodismo contemporáneo en relación a la obra de Gerda Taro. Tesis Doctoral (inédita) Universidad Jaume I. Castellon. 
CARRASCO MARQUÉS, Martín (1992): Catálogo de las primeras tarjetas postales de España impresas por Hauser y Menet (1892-1905), Ed. Casa Postal. Madrid.

CARRASCO MARQUÉS, Martín (2004): Las tarjetas postales ilustradas de España circuladas en el siglo XIX, EDIFIL. Madrid.

CHÉROUX, Clément; ESKILDEN, Ute (2008): La Photographie Timbrée: L'inventivité Visuelle de la Carte Postale Photographique: à Travers les Collections de Cartes Postales de Gérard Lévy y Peter Weiss. Ed. Steidl Verlag. Winterthur.

CULP DARRAH, W. (1981): Cartes de Visite in Nineteenth Century photography. Ed. Stan Clark.

DEL CAMPO, Antonio (1903): Tarjetas postales, Santander.

PALÁ LAGUNA, F., "La tarjeta postal ilustrada”. Versión digital: http://www.dpz.es/turismo/cadiz-zaragoza/doc/pala.pdf

RIEGO AMÉZAGA, Bernardo y ALONSO LAZA, Manuela (eds.) (1997): Santander en la tarjeta postal ilustrada (1897-1941). Historia, coleccionismo y valor documental, Fundación Marcelino Botín. Santander.

RIEGO AMÉZAGA, Bernardo (2001): La Construcción Social de la Realidad a través de la Fotografía y el grabado informativo en la España del siglo XIX. Ed. UC.

RIPERT, Aline y FRÈRE, Claude (1983): La carte postale. Son histoire, sa fonction social. CNRS Editions. París.

SÁNCHEZ SÁNCHEZ, Isidro et alli (2007): "Evocación, Historia y Tarjetas postales entre dos repúblicas (1869-1939)", en Fotografía y Patrimonio, II Encuentro en Castilla la Mancha. Centro de Estudios de Castilla la Mancha. Ciudad Real.

TEIXIDOR CADENAS, Carlos (1999): La tarjeta postal en España, 1892-1915, Espasa Calpe. Madrid.

VEGA, Carmelo (2010): Lógicas turísticas de la fotografía. Ed. Cátedra. Madrid. 